\title{
NETWORK SECURITY FUNDAMENTALS
}

\author{
By Peter Norton and Mike Stockman \\ SAMS, 2000. ISBN: 0-672-31691-9.
}

$\mathrm{T}$ his book is designed to give network administrators of any level an overview of the issues and practices involved in keeping a computer network safe from any source, whether outside or inside the network. This area has been important since the first computers started talking to each other, but interest in this area has grown in recent years as more computers have networking cards and software built in, and as the cost of the networking infrastructure (cabling, hub, routers, and so on) has plummeted.

An even stronger driving force behind the interest in networking security has been connectivity to the Internet, which is not only more available than ever, but is also becoming faster and more accessible. "Always On" is a big marketing point for cable modems and digital subscriber lines, but the same connection that allows the access to the Internet at will also allows others to enter your network by the same path. This book shows how to restrict access so that you have as much control as possible over who can see and change your systems and data.

The news has been full of reasons why you need to stay informed on networking security. Crackers are constantly inventing new ways to enter your network through bugs in your servers, flaws in Web browsers, misconfigured access privileges, weak passwords, trojan horse programs, and numerous other methods. Even worse is that newly discovered security holes are soon picked up by "script kiddies," or people who don't have the skill or intelligence to discover these flaws themselves but who seem to have unlimited time on their hands to exploit the flaws once others make them known.

There is no perfectly secure server, router, network operating system, or any other networking component. There is no such thing as uncrackable network, except for one that isn't connected at all. The most powerful element you have working for you are preparation and information. This book can help you get started on both, so you can prepare your network against most intrusion and set your systems up to notify if 
an attack does occur. It can also help you with information about how attacks work and where to go to find the latest updates on flaws and fixes, and what to replace with more secure alternatives.

Your allies in this fight to secure your information and systems are the security analysts, the government and educational security forces such as CERT and GIAC, and the developers of security products you can add to your network for protection, such as firewalls, routers, and intrusion detection systems. These allies are mentioned throughout this book, as well as listed in an appendix.

This book also describes how to win the cooperation of your primary allies in the fight against network crackers: your users. Through the education of your users, you can prevent social-engineering attacks (where the users are tricked into providing illicit access to your network), password-cracking attacks (where too simple passwords provide a hole into your network), and other attacks from inside and outside of your network. Without the education and cooperation of your users, none of the solutions in this book will keep you safe for long.

Finally, this book describes ways in which you can provide, rather than restrict, access to your network, but in a safe way that supports your users while protecting your resources.

\section{About the authors:}

Computer software entrepreneur and writer Peter Norton established his technical expertise and accessible style from the earliest days of PC. His Norton Utilities was the first product of its kind, giving early computer owners control over their hardware and protection against myriad problems. His flagship titles, Peter Norton's DOS Guide and Peter Norton's Inside the PC (SAMS Publishing) have provided the same insight and education to computer users worldwide for nearly two decades. Peter Norton's former column in $P C$ Week was among the highest regarded in that magazine's history. His expanding series of computer books continues to bring superior education to users, always in Peter's trademark style, which is never condescending nor pedantic. From their earliest days, changing the "black box" into a "glass box," Peter's books, like his software, remain among the most powerful tools available to beginners and experienced users, alike.

Mike Stockman has been writing documentation and training users in the United States and Europe for more than 12 years. He has written about networking products for Windows 3.x, 95, and NT, as well as numerous other projects for Windows, MacOS, Solaris, and other operating systems. 